\title{
Applicability Analysis of Single-Machine Equivalent Method for Modeling Wind Farm Containing Full-Converter Wind Turbine Generators with PMSG
}

\author{
Su Xunwen ${ }^{1,2}, X_{\text {X Dianguo }}{ }^{1}$, Bu Shupo ${ }^{3}$ and Zheng Shuang ${ }^{2}$ \\ ${ }^{1}$ School of Electrical Engineering and Automation \\ Harbin Institute of Technology \\ 92 West Dazhi Street, Nan Gang District, 150001 Harbin (China) \\ Phone number:+86451 +8645186402005, e-mail: suxunwen@163.com, xudiang@hit.edu.cn \\ ${ }^{2}$ School of Electrical and Information Engineering,Heilongjiang Institute of Science and Technology \\ e-mail: zs1980225@126.com \\ ${ }^{3}$ Department of electronics and Communication Engineering,Suzhou Institute of Industrial Technology \\ e-mail: bushupo@163.com
}

\begin{abstract}
For the analysis of the applicability of singlemachine equivalent method for modeling wind farm containing full-converter wind turbine generators(WTG) with permanent magnet synchronous generator(PMSG), at frist, single-machine equivalent methods of equivalent model are provided, then the detailed and equivalent wind farm model is built on simulation software DIgSILENT/Power Factory platform. At last, for wind speed fluctuations and grid disturbance, the applicability of single-machine equivalent method is analyzed by comparing dynamic response at point of interconnection between equivalent model and the detailed model of wind farms. Results show that this method is suitable for the dynamic equivalent modeling of wind farm containing directly driven wind turbine with PMSG in certain situations.
\end{abstract}

\section{Key words}

Equivalent method, full-converter wind turbine generators with PMSG, wind farm, modeling

\section{Introduction}

With the increasing of the capacity and number of largescale wind farms integration, the fluctuations and intermittent of wind power output will challenge power system security and stability greatly. Theory and method for dynamic equivalent modeling of wind farms has become an urgent basic and applied research project[1].

At present, the discussion of the relevant the dynamic equivalents modeling of the wind farm is concerned mainly in fixed-speed wind turbines and doubly fed induction generator wind turbines[2-12], and the literature of dynamic equivalence methods are few studied for modeling wind farm containing full-converter WTG with PMSG. In [13], the dynamic equivalent permanent magnet synchronous generator wind farm modeling method applicable to magnetic transient simulation analysis is given . For a braking resistor in the DC circuit as as the LVRT control,according to wind speed clustering equivalents, the equivalent of the wind turbine model and the simplified method of crowbar model are given[14] . But dynamic equivalents method is rarely studied under the wind speed fluctuations, also when the LVRT control is neglected, or when the over-dimensioned capacitor is taken as the LVRT control, equivalents method is rarely studied. Currently,common equivalent method is singlemachine equivalent method, People are very concerned about the applicability of single-machine equivalent model.

\section{WTG with PMSG Model}

In the PMSG model, the flux is assumed to be sinusoidally distributed along the air gap and no damping winding is considered. The mathematical equations are constructed by aligning the d-component of machine vectors to the rotor flux. The dq-axis voltage equations of the machine have the following form.

$$
\begin{gathered}
v_{d s}=R_{s} i_{d s}-\omega_{r} L_{q s} i_{q s}+L_{d s} \frac{d i_{d s}}{d t} \\
v_{q s}=R_{s} i_{q s}+\omega_{r} L_{d s} i_{d s}+\omega_{r} \psi_{p m}+L_{q s} \frac{d i_{q s}}{d t}
\end{gathered}
$$

where $R_{s}$ is the stator resistance; $v_{d s}$ and $v_{q s}$ are the $d$ and $q$ components of the terminal voltage vector, respectively ; $i_{d s}$ and $i_{q s}$ are the $d$ and $q$ components of the stator currents, respectively; $L_{d s}$ and $L_{q s}$ are the $d$ and $q$ components of the stator inductance, respectively; $\omega_{r}$ is the synchronous electric angular velocity; $\Psi_{p m}$ is the rotor flux linkage.

The dynamics of the dc-link can be expressed as

$$
C \frac{d u_{d c}}{d t}=\frac{P_{g e n}-P_{c}}{C u_{d c}}
$$


where $P_{g e n}$ and $P_{c}$ are the generator and grid-side converter active power, respectively; $C$ is the dc-link capacitance; $u_{d c}$ is DC voltage.

Full-Converter model used in this work has been constructed in the dedicated power systems analysis software package PowerFactory supplied by DIgSILENT $\mathrm{GmbH}$. The converter controllers are used to regulate the converter currents and voltages and the active power and reactive power output of the FCWTG. Fig.1 shows the block diagram of the control for the machine-side rectifying converter. The rectifying converter is used to control the generator AC voltage $V a c$ and the output active power $\mathrm{P}$ of the PMSG.
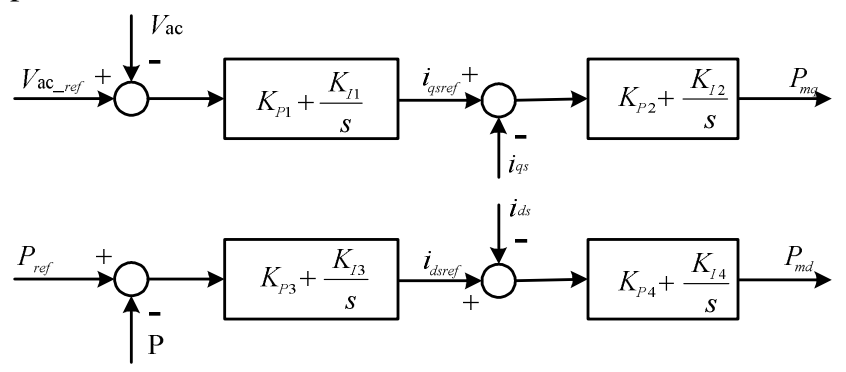

Fig. 1. Generator-side converter control block diagram

Fig. 2 shows the control scheme for the grid-side inverting converter. The inverting converter is used to control the reactive power $Q$ grid and the DC link voltage $U d c$.

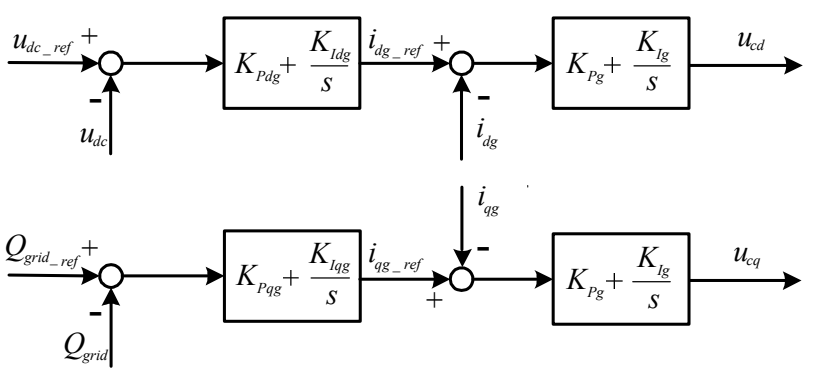

Fig. 2. Grid-side converter control block diagram

\section{Single-Machine Equivalent Method}

According to the fault isolation of double pulse width modulation (PWM) converters for directly driven wind turbine with permanent magnet synchronous generator (PMSG), when the low voltage Ride-through (LVRT) control is neglected, or when the over-dimensioned capacitor is taken as the LVRT control, the wind farm with PMSG can be equivalent into a wind turbine generator. Single-machine equivalent wind farm model is shown in Figure 3.

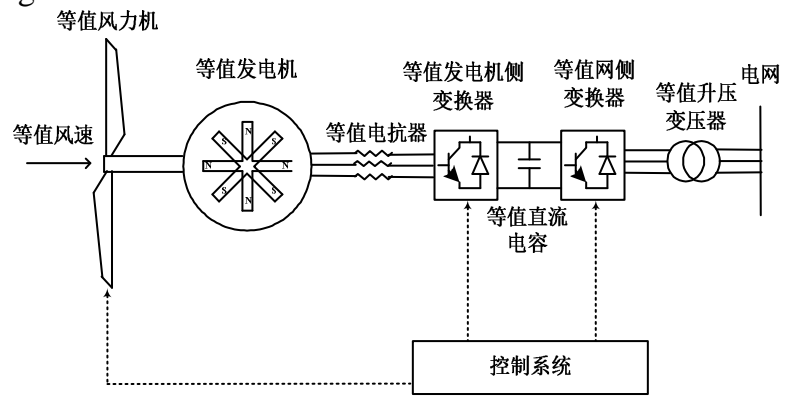

Fig. 3. Single-machine equivalent wind farm model
As shown in Fig.3, the parameters of the various parts of equivalent model are calculated as follows:

A. Generator parameters

$$
\left\{\begin{array}{l}
S_{e q}=n S, x_{m_{-} e q}=\frac{x_{m}}{n}, x_{1_{-} e q}=\frac{x_{1}}{n}, r_{1_{-} e q}=\frac{r_{1}}{n}, x_{1_{-} e q}=\frac{x_{1}}{n} \\
x_{2 d_{-} e q}=\frac{x_{2 d}}{n}, x_{2 q_{-} e q}=\frac{r_{2 q}}{n}, x_{2 d_{-} e q}^{\prime \prime}=\frac{x_{2 d}^{\prime \prime}}{n}, x_{2 q_{-} e q}^{\prime \prime}=\frac{x_{2 q}^{\prime \prime}}{n}
\end{array}\right.
$$

Where $n$ is the number of wind turbines; Subscript eq indicates equivalent abbreviations ; $S$ is generator apparent power; $x_{1}$ and $r_{1}$ are the generator stator resistance and reactor, respectively; $x_{2 \mathrm{~d}}^{\prime}$ and $x_{2 \mathrm{q}}^{\prime}$ are the $d$ and $q$ components of the transient reactance, respectively ; $x_{1}^{\prime}$ is transient reactance; $x_{2 \mathrm{~d}}^{\prime \prime}$ and $x_{2 \mathrm{q}}^{\prime \prime}$ are the $d$ and $q$ components of the sub-transient reactance, respectively.

B. Shafting parameters

$$
H_{g_{-} e q}=n H_{g}, H_{t_{-} e q}=n H_{t}, K_{s_{-} e q}=n K_{s}
$$

where $H_{t}$ and $H_{g}$ are the inertia for turbine and generator, respectively; $K_{s}$ is spring for turbine.

C. Transformer parameters

$$
S_{T_{-} e q}=n S_{T}, Z_{T_{-} e q}=\frac{Z_{T}}{n}
$$

where $S_{T}$ and $Z_{T}$ are apparent power and impedance of transformer, respectively.

D. Reactor parameters

$$
S_{D_{-} e q}=n S_{D}, Z_{D_{-} e q}=\frac{Z_{D}}{n}
$$

where $S_{D}$ and $Z_{D}$ are apparent power and impedance of reactor, respectively.

\section{E. Control parameters}

In addition to the power measurement module, equivalent wind turbine control parameters are the same as parameters of pre-equivalent wind turbine. Power measurement module need for capacity adjustment, and its control point need to be adjusted according to the post-equivalent bus. The reference capacity of measurement equivalent modules of the generator-side and grid-side converter are calculated as follows:

$$
S_{e q}=n S
$$

F. Converter parameters

$$
\begin{aligned}
& S_{e q}=n S \\
& C_{e q}=n C
\end{aligned}
$$

where $S_{e q}$ is apparent power of converter; $c_{e q}$ is the dclink equivalent capacitance.

G. Reactive power reference value of wind turbine 


$$
Q_{\text {ref_eq }}=\sum_{i=1}^{n} Q_{\text {ref_i }}
$$

where $Q_{\text {ref }}$ is reactive power reference of wind turbine.

\section{H. Cable charging capacitor}

As the voltage difference of wind turbines can be neglected in wind farm, the equivalent charging capacitance is equal to sum of all cables equals charging capacitor before equivalence.

\section{Equivalent wind speed}

When all wind turbines are rated power output, the equivalent wind speed is calculated as follows:

$$
v_{e q 1}=\frac{1}{n} \sum_{i=1}^{n} v_{i}
$$

When wind turbines are not all rated power output, at first active power of each wind turbine are obtained through wind speed and wind power curve, and then calculate the average power, at last the equivalent wind speed is calculated by the wind power curve. The equivalent process is as follows, the output power of the $k$ th wind turbine is calculated as follows:

$$
p_{k}=f\left(v_{k}\right)
$$

where $f$ is the fitting function of the curve of wind speed and power ; $v_{k}$ is wind speed of the $k$ th wind turbine. Equivalent wind speed is calculated as follows:

$$
v_{e q}=f^{-1}\left(\frac{1}{n} \sum_{i=1}^{n} f\left(v_{i}\right)\right)
$$

\section{Simulation results}

Figure. 4 shows the configuration of the wind farm used for this study. The wind farm under consideration has 9 direct-drive permanent magnet synchronous wind turbine of $1.5 \mathrm{MW}, 3.3 \mathrm{kV}$ each. A transformer $35 / 3.3 \mathrm{kV}$ boosts up the voltage and a medium voltage line at $35 \mathrm{kV}$ connects it to the wind farm substation. The wind farm substation present a transformer110/35 kV coupling at $110 \mathrm{kV}$ the wind farm to the power network at the point of common coupling (PCC). wind farm model is built on simulation software DIgSILENT/Power Factory platform. Electric parameters of wind farm under consideration are shown in Table I.

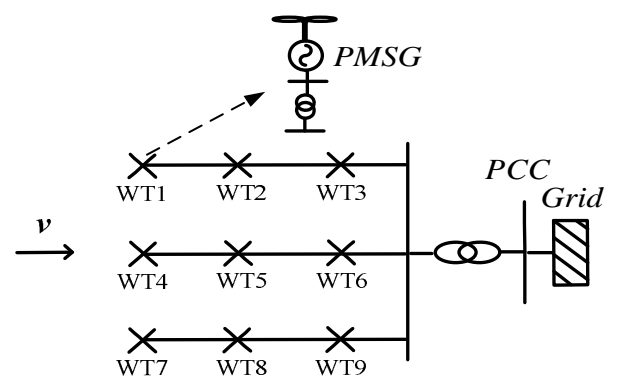

Fig. 4. Single line diagram of wind farm
Table I. Electric parameters of wind farm

\begin{tabular}{ccccc}
\hline \multirow{5}{*}{ Generator } & $S / \mathrm{MW}$ & 1.5 & $U / \mathrm{kV}$ & 3.3 \\
& $r_{1}(\mathrm{pu})$ & 0.0001 & $x_{1}(\mathrm{pu})$ & 0.05 \\
& $x_{2 \mathrm{~d}}^{\prime}(\mathrm{pu})$ & 1.5 & $x_{2 \mathrm{q}}^{\prime}(\mathrm{pu})$ & 1.5 \\
& $T_{1}^{\prime} / \mathrm{s}$ & 0.1 & $x_{1}^{\prime}(\mathrm{pu})$ & 0.25 \\
& $x_{2 \mathrm{~d}}^{\prime \prime}(\mathrm{pu})$ & 0.17 & $x_{2 \mathrm{q}}^{\prime \prime}(\mathrm{pu})$ & 0.17 \\
& $T_{2 \mathrm{~d}}^{\prime \prime} / \mathrm{s}$ & 0.02 & $T_{2 \mathrm{q}}^{\prime \prime} / \mathrm{s}$ & 0.05 \\
\hline Wind turbine & $S / \mathrm{MW}$ & 1.5 & $r / m$ & 30 \\
\hline Reactor & $S / \mathrm{MW}$ & 1.7 & $U / \mathrm{kV}$ & 3.3 \\
\hline \multirow{2}{*}{ Converter } & $S / \mathrm{MW}$ & 1.7 & $U / \mathrm{kV}$ & 3.3 \\
& $U / \mathrm{kV}$ & 6.6 & $C / \mathrm{uF}$ & 1000 \\
\hline Transformer 1 & $S / \mathrm{MVA}$ & 1.7 & $X_{\mathrm{t}}(\%)$ & 6 \\
\hline Transformer 2 & $S / \mathrm{MVA}$ & 50 & $X_{\mathrm{t}}(\%)$ & 11 \\
\hline
\end{tabular}

A. wind fluctuations in the wind farm

The wind speed of the wind farm consider influence of wake effect and time delay. Assuming winds blow from left to right across wind farm and each row of wind turbines have the same wind speed. Figure. 5 shows wind speed of three rows wind turbines (In Figure.5, 1, 2 and 3 represent each row of wind turbines, respectively), equivalent wind speed by using equivalent the method given in this paper(The short red line in Figure.5), and the average wind speed of three rows wind turbines(dotted linein Figure.5). Figure.6 compares the active power, reactive power and voltage magnitude of the detailed model(solid line in Figure.5) and singlemachine equivalent model at the PCC by using equivalent wind speed and the average wind speed, respectively.

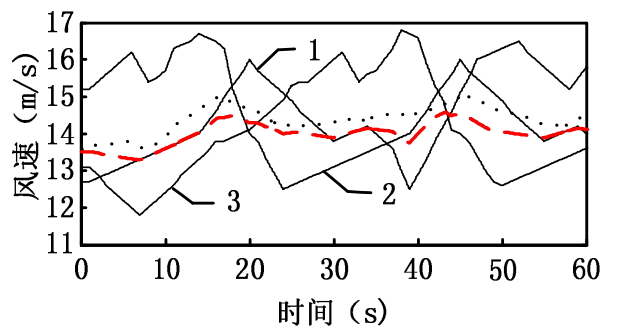

Fig. 5. wind speed fluctuations
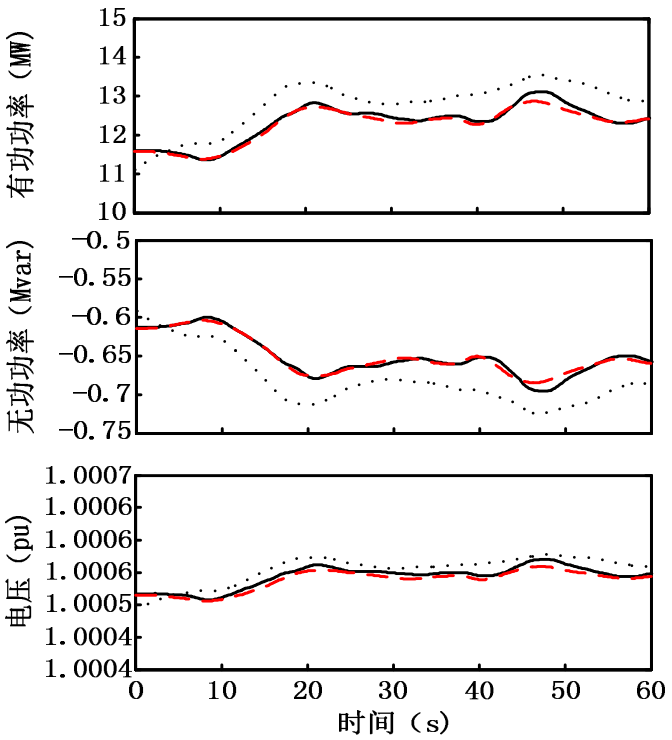

Fig. 6. Dynamic response of wind farm at point of interconnection under wind speed fluctuations 
As explained in Fig. 6, equivalent models by using the equivalent wind speed provide higher accuracy than equivalent models by using the average wind speed. The simulation results show that the proposed equivalent model provides the same accuracy the dynamic characteristics as the detailed model.Thus the validity of the equivalent method is confirmed under wind speed fluctuations.

\section{B. Grid Faults}

In order to evaluate the validity of single-machine equivalent method for power system transient studies, a three-phase short circuit is applied at the PCC at $\mathrm{t}=0.5 \mathrm{~s}$ and is clear in $150 \mathrm{~ms}$. Wind speed of all wind turbines are shown in Table II. For transient stability analysis, it can be assumed that wind speed is constant during the fault occur. Figure. 7 compares the active power, reactive power and voltage magnitude of the equivalent model and the detailed model of the wind farm at the PCC, respectively.

Table II. Wind speed of wind turbine

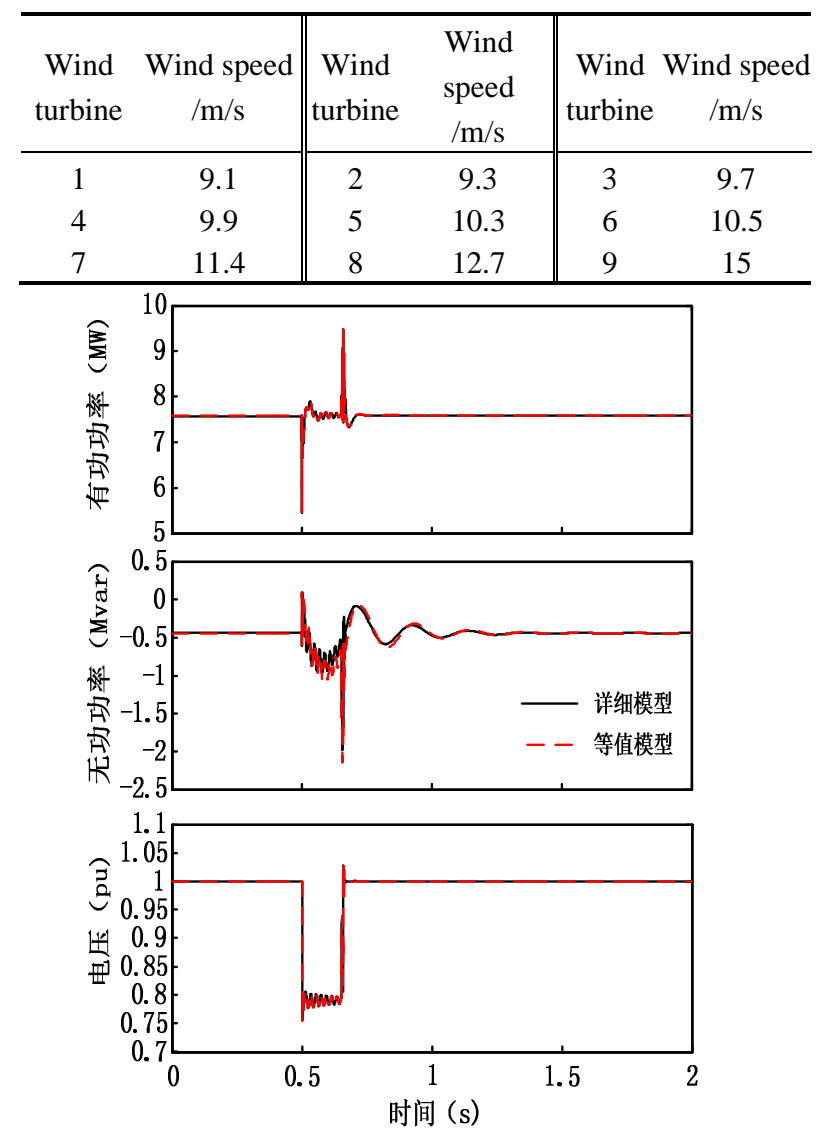

Fig. 7. Dynamic response of wind farm at point of interconnection under grid disturbance

Figure. 7 show that the proposed equivalent model provides the same accuracy the dynamic characteristics as the detailed model for active power and voltage magnitude, only the accuracy of reactive power of proposed equivalent model degrades slightly. It have two reasons for error as follows: (1) equivalent model ignores equivalence of wind farm cable impedances; (2) During failure the speed and pitch angle of wind turbine have small changes, these will result in a smaller equivalent error. The simulation results show that single-machine equivalent method is suitable for the dynamic equivalent modeling of wind farm containing directly driven wind turbine with PMSG under faults.

\section{Conclusion}

According to the fault isolation of double pulse width modulation (PWM) converters for directly driven wind turbine with permanent magnet synchronous generator (PMSG), when the low voltage Ride-through (LVRT) control is neglected, or when the over-dimensioned capacitor is taken as the LVRT control, the wind farm with PMSG can be equivalent into a wind turbine generator, and the parameters calculating methods of equivalent model are provided. The applicability of single-machine equivalent method is analyzed by simulations. The simulation results show that equivalent models by using the equivalent wind speed provide higher accuracy than equivalent models by using the average wind speed under wind speed fluctuations, and the proposed equivalent model provides the same accuracy the dynamic characteristics as the detailed model under faults. It can conclude that this method is suitable for the dynamic equivalent modeling of wind farm containing directly driven wind turbine with PMSG.

\section{Acknowledgement}

This work was supported by Foundation of Heilongjiang Educational Committee (No. 12521467), Major project of Delta Science \& Technology Educational Development Program(No. DREM2012001), Key Program of National Natural Science Foundation of China(No. 51237002), National Natural Science Foundation of China (No. 51107015), Applied Basic Research Project of Suzhou Bureau of Sciences and Technology (No. SYG201119), China Postdoctoral Science Foundation(No. 20110491042) and Heilongjiang Postdoctoral Financial Assistance(No. LBH-Z11150).

\section{References}

[1] Slootweg J G, Kling W L. Aggregated modelling of wind parks in power system dynamics simulations. IEEE PowerTech Conference, Bologna, Italy, 2003.

[2] Fernández L M, García C A, Saenz J R. Equivalent models of wind farms by using aggregated wind turbines and equivalent winds. Energy Conversion and Management, 2009, 50(3): 691-704.

[3] Hector A. Pulgar-Painemal, Peter W. Sauer.Towards a wind farm reduced-order model[J]. Electric Power Systems Research, 2011, 81: 1688-1695.

[4] Jacques Brochu, Christian Larose, Richard Gagnon. Validation of Single- and Multiple-Machine Equivalents for Modeling Wind Power Plants[J]. IEEE Transactions on Energy Conversion, 2011, 26(2): 532-541.

[5] PÄoller M, Achilles S. Aggregated wind park models for analyzing power system dynamics. 4th International Workshop on Large-Scale Integration of Wind Power and Transmission Networks for Offshore Wind Farms, Billund, Denmark, 2003. 
[6] Akhmatov V. An aggregated model of a large wind-farm with variable-speed wind turbines equipped with doublyfed induction generators. Wind engineering, 2004, 28 ( 4) : 479-488.

[7] Mi Zengqiang, Su Xunwen, Yang Qixun, et al. MultiMachine representation method for dynamic equivalent model of wind farms. Transactions of China Electrotechnical Society, 2010, 25(5): 162-169.(in Chinese)

[8] Mi Zengqiang, Su Xunwen, YU Yang, et al. Study on Dynamic Equivalence Model of Wind Farms with Doubly Fed Induction Generator Wind Turbines. Automation of Electric Power Systems,2010, 34 ( 17 ) : 72-77.(in Chinese)

[9] Su Xunwen, Mi Zengqiang, WANG Yi, et al. Applicability and Improvement of Common-Used Common Equivalent Methods for Wind Farms. Power System Technology, 2010 , 34 (6) : 175-180.(in Chinese)

[10] Perdana A . Dynamic models of wind turbines: a contribution towards the establishment of standardized models of wind turbines for power system stability studies : [Doctoral Dissertation]. Sweden: Chalmers University of Technology, 2008.

[11] García-Gracia M, Comech M P, Sallán J, et a . Modelling wind farms for grid disturbance studies . Renewable Energy, 2008, 33 (9) : 2109-2121.

[12] K Rudion . Aggregated modelling of wind farms : [Doctoral Dissertation] . Germany : Otto-von-GuerickeUniversitat Magdeburg, 2008.

[13] Yang Xiaobo, Yue Chengyan, Xie Hailian . An Aggregation Method of Permanent Magnet Synchronous Generators Wind Farm Model for Electromagnetic Transient Simulation Analysis . Power System Technology, 2011, 35(2): 115-120.

[14] Conroy J, Watson R. Aggregate modelling of wind farms containing full-converter wind turbine generators with permanent magnet synchronous machines:transient stability studies. Renewable Power Generation, 2009, 3(1): 3952 . 